\title{
Walking within Film: Gilbertson and Tait and Insignificant Steps Within Landscape
}

\author{
Two Scottish women film-makers, Jenny Gilbertson and Margaret Tait both encounter \\ walking within $20^{\text {th }}$ century Island culture. This study considers the function itself within \\ cinema as an occurrence of landscape. To this end it treats their earlier work, \\ investigating it through a Deleuzian cinematic framework. The predominantly visual field \\ of film is demonstrated as rendering walking relatively invisible, with particular \\ relevance to the action image. The wider investigative construct of affect is also observed \\ as incompatible. Only in Tait's later work does the cinema of chronology convey a \\ satisfactory explanation of walking, but this is confined to the schema of 'organic' \\ documentary. Finally, walking in relation to landscape is considered as conceptual act. \\ This employs a model suggested by Jean-Luc Nancy that is only partially attainable \\ through cinema, so that the role of the medium itself is open to doubt.
}

\section{Introduction.}

The task of walking is familiar to the $20^{\text {th }}$ century cultures that would be enthused or impacted by cinema, a necessary labour and an inexpensive recreation. From its earliest incarnation, crowds of walkers are marshalled to evoke the dynamics of urban life before the camera. Walking may also function as individual portrayal; within the Scottish modernist tradition, the neo-realist film-maker Margaret Tait employs it as a fluent phrasing of character. For one of her more widely distributed films, the miniature 1964 biopic of the poet Hugh MacDiarmid, her subject plays to camera, walking the pavement edge, or a low wall, in a sequence that could be suggested as referencing the ambling languages of the silent comedians. ${ }^{1}$ For Tait's purpose, this is also a walking line that reflects the written line on the page, or spoken sound-line of poetry, each of them treated earlier in the film. The parallel between movement and language is appropriately leading towards an understanding of walking within the context of Enlightenment thought, as a means to a productive harmony of mind and body. However, and this is the central concern of this article, for all the spectatorship, the deliberate observation of walking, even Tait here is unable to realize its most critical function, the "moving two-legged beast" to adopt Frédéric Gros's term $(2014,7)$. Walking enters into the intellectual and spiritual tradition as an experiential mode of movement through landscape and as an encounter which must be viscerally undertaken before the subject may speak with authority. Within cinema however, the camera's mechanized extension of the eye professes a correspondence in capacity, but instead refuses this total alignment with the body. The film-maker herself cannot walk, her camera must be firmly held, employing a tripod or rails and even when hand-held, it must avoid shaking and above all, must avoid the literal nausea which the frames would induce if following the uneven and repetitive movement of walking. Film visualizes walking, but the alignment lacks rhythmic correspondence: it is dumb where poetry or music have capacity for eloquence. Out of that contradiction this article will draw a

\footnotetext{
${ }^{1}$ The films discussed at length in this article can be accessed at the Scottish Screen Archive collections available online at http://movingimage.nls.uk/
} 
case-study of two Scottish women film-makers, Tait on the Orkney Islands and the early work of her 1930s predecessor Jenny Gilbertson (née Brown) on the Shetland Islands. In order to investigate walking itself, it will draw upon Gilles Deleuze's constructs of action and time image and also briefly consider the functioning of affect, as a means of exploring the cinematic occurrence of this action which so evades accountability upon the screen. Its conclusion however will turn to a passage within the aesthetic work of Jean-Luc Nancy, so that the prior problem of envisaging walking within landscape may be foregrounded in relation to film's capacities.

\section{The Function of Walking}

Gros and Rebecca Solnit are both sophisticated empirical researchers, each dedicating a purpose to walking, in his case the dislocation from previous encumbrance and the freed natural encounter and in hers, the initiation of an investigation, ritual or meditation. They must both establish an irrelevance of walking, 'child's play' for Gros, 'unconsidered locomotive means' for Solnit, as a brief preliminary before exploring this abundance of significance (Gros 2014, 1-7) (Solnit 2001, 3-4). Within the sphere of developmental psychology, the child's acquisition of walking is observed as a long and complex environmentally influenced learning process, one in which the necessary strength and balance are constructed as muscular and neuronal habits; it is no innocent occurrence, but a constructed cognition within the body (Adolph, Vereijken and Shrout 2003). This developmental stage is forgotten, rendered invisible, unless by accident or chance the capacity must be re-learnt; research into how walking occurs is concentrated most productively upon the robotic field, where stumbling translations to the machine return it afresh as an urgent question (Alexander 2005; Pfeiffer and Inoue 2007). Correspondingly for an understanding of walking within cinema, it is essential to ask how on-screen significance arises for an activity embedded within human experience, but only actually observed if specific allocation is made. The selection of a Deleuzian approach is no innocent choice in relation to this activity, but the decision to work with a philosophy of cinema that is dedicated to the specificity of the cinematic as opening up new methods of thinking. The problem here is neither one of paralleling a universal psychological experience on screen, nor of prioritizing particular occurrence within walking. Cinematic visual representation fails as a direct phenomenological parallel, it cannot for example match the compensatory acceleration of their own sight-in-motion which the walking subject develops alongside physical movement (Durgin 2009). Moreover, cinematic potential is open to all occurrences, so that a democratization of these occurs; neither 'tactical' nor "memorial' approaches to walking are inherent choices; the individual film itself must alight upon its version. This meritocratic medium makes a demand of every represented element that when 'on screen' it perform a function, emerging out of the frame to occupy the attention of the audience for a reason, entering into a visual semiotics. Walking in itself requires not only occurrence, visual on-screen representation but also the underlying function which raises it to attentive observation. To this end, Deleuze's discussion of action and time develops an invaluable understanding of cinema both as a tool for conceptualization in its own right, and as a saturation of experience unique to the moving image - and he adopts the term "privileged instant" for this visibility $(1986,4)$. Gros and Solnit may access an eloquent evocation of walked landscape through their writing, but within cinema such amalgamated association would evoke a complex grouping of performative functions, functions moreover which are at a screen's distance away. The reasoning behind these 
and their active rendering on screen may be traced through the Deleuzian priorities of cinematic intent.

\section{The Sphere of Action.}

\section{i. Gilbertson: the absent walker}

To an extent, parallels may be drawn between the two Scottish film-makers here, in that each woman works with the pressures facing Island crofting cultures and the preservation of traditional identities in this context, but a critical mid-century gap also separates them. The act or theme of walking plays a distinct but limited role in the earlier work. Gilbertson, starting her career in 1931, was living half a year on the Shetland Islands, gathering material with a $35 \mathrm{~mm}$ camera, for the film A Crofter's Life in Shetland. She was influenced by John Grierson, and works as a documenter, deliberately recording and showing traditional agriculture and customs prior to their imminent disappearance (Pipes et al. 2006, 134). Her films emerge in the context of ethnographic and folk studies within Scotland, her contemporaries Werner Kissling on Eriskay and Margaret Fay Shaw on South Uist also employing residence, film and photography to the same purpose. In Gilbertson's early work especially, the camera can be handheld, but remains static, a tool for observation, shots picking up a series of individual instances, and it is in the idiosyncratic quality of her alert and wide ranging selection and perception here that her particular contribution as a film-maker lies, particularly as it provides dignity to her marginalized subjects. Her unpublished diary from the period also demonstrates some adherence to the ethnographical needs of participant research, accustoming herself to the seasonal labour of crofting as a visitor within the community (Gilbertson 1931). Walking thus emerges as an observed theme within her work because it was a daily obligation that crofters walked long distances, often on rough ground and in all weathers, to cut peat, tend to livestock or travel between farms. As Gilbertson filmed, the availability of wheeled transport, especially motor vehicles, was overtaking this way of life, rendering the task even more visible as a lost habit. Thus for example, her small film Scenes from a Shetland Croft Life explaining peat-cutting incorporates shots of the long journeys men and women made to collect the fuel, figures stooped beneath baskets and the women knitting incessantly as they walked. When, later in 1933, she undertook a longer narrative film The Rugged Island: A Shetland Lyric, drawing out a fictional romance to convey the pressures placed upon young people to emigrate, walking functions as a dramatic element. The two protagonists walk together when in harmony (framed by the sea-shore), but when the man decides on emigration, the woman refuses to join him and walks jerkily and angrily with her family instead. However these observations are brief, and distant, the camera holding back and observing in long shot from a static position. Watching these episodes the viewer would not realize that Gilbertson's early diary also reveals her to be a passionate and intensive walker in her own right. She undertakes long treks across the island landscape, encountering its bird-life and climate, noting the constant presence of the fishing boats or the people she meets, and also her own feelings for the location. This is absent however, within the documentary and ethnographic frames of her films where the act of walking can only function as a component within a larger explanation. The cinematic task here is to convey turf-cutting as a traditional method of gathering fuel, unique to island culture. All elements - specialist tools or gender-specific roles, are assembled in this narrative, pointing up the larger social construct of familial or communal labour. 


\section{ii. Action Cinema and Chosen Judgements}

In the context of this approach, walking itself is an action possessed of limited cinematic capacity - for all its presence within the culture. A brief consideration of Gilbertson's early work in the light of the Deleuzian action-image enables a fuller understanding of this restriction. Across the two volume study of cinema, Deleuze undertakes a development of the philosophy of Henri Bergson which addresses our perception of time through our immediate understanding of movement. Thus, our immediate experience is of closed sets of movement, an abstraction or identification of individual segments, which we link together - and these are the parts we can perceive. From this we construct an understanding of time, as a larger whole, a longer duration and a phenomenon which opens up behind us; it is after all, constructed from changes that are not open to our immediate perception (Deleuze 1986, 12). Working with Deleuze therefore directs one towards both a close consideration of our most immediate responses to on-screen action, and also to an intuition of philosophical significance within the aesthetics of cinema. Meaningful instances or sequences of action, of the type Gilbertson and other ethnographic observers constructed in the 1930s, are the preserve of the action image, of a cinema which looks to provide a readable significance for the spectator. Ronald Bogue distinguishes this "classical cinema" in his detailed enunciation of the tripartite Deleuzian sub-division of action image into inter-related elements of perception, action and affect (2003). Deleuze discusses a cinema in which the spectator experiences affect through the "virtual conjunction" of divisions within montage, instances of connection and separation within the affective moment .He emphasises these as 'pure possibilities, pure virtualities, which will be accomplished in the light of particular conditions' (1986,108-109).

In Gilbertson's short film In Sheep's Clothing (1932) sheep are being gathered and "rooed," their fleeces plucked by hand. An animal is frightened and an old woman reaches forward to reassure it, we are caught up in an instance of perception-image, shifting through action-image to affect-image within the interval of occurrence, as we respond to the nervous alienated animal head and the human action sharing the frame. Our condition is the expectation of strangeness in a marginal culture, the tied animal's situation conveys a wealth of information, within which context the coming together of the two faces moves us to a tactile sense of affect. This sphere of possibility is also a sphere of responsibility for Deleuze, in that we undertake choices, when deciding our affective connections here, and corresponding ethical values are attached to our reading of the image. We (or 1930s viewers) are an urbanized audience, shocked to hygienic reservations by the close affective connection revealed between woman and animal within a marginal community. In the classical cinema such choices are attached to the dynamics of the on-screen protagonists, and the film-maker has at their command the vocabulary of montage and of lighting to convey their corresponding ethical positioning. D. N. Rodwick, commenting on this communal process, suggests it as 'an image that solicits thought and draws us to a space of moral reasoning' $(2010,106)$. We have to observe therefore that, even within a documentary mode, the classical cinema embeds a distinctive judgemental presence within the treatment of its protagonists, and we must also note, through the understanding that Deleuze has provided to us of the closeness and imminence with which that presence occurs, that it can be integral even to the smallest of choices. However, following these frames, we may also start to understand the position of walking: that it is an action which possesses only a small inherent capacity to hold attention within in this context. Unlike other actions chosen for development, it cannot carry the larger themes that document a marginal culture, 
because these must work with actions sufficient to provoke a response that relates to our perception of the character's ethical world. Gilbertson looks to the ethnographic strangeness of the marginal community for her judgemental action images, playing down her own walking experience of landscape. Thus she emerges as a positive example for early $20^{\text {th }}$ century cinema, but illuminates walking only as negative space.

\section{The Sphere of the Human: Approaches to Walking}

\section{i. The Limits of Affect.}

Deleuze conveys the hierarchical underpinnings of our affective engagement and also of the ethical consequences with which we are involved as a result. Walking may occur for Gilbertson, but is insufficiently empowered for information, or affective connection in its own right: it is a watched motion without the impact of our perceiving an action. At this point it is imperative to consider the affective inheritance which emerges from Deleuzian aesthetics and parallel fields of activity. Affect as a field of study in its own right, is positioned as a vital experiential force and a prior element within bodily experience, one that occurs even before emotion or cognition. Barbara Kennedy has identified this element within Deleuze's interest in the perpetual state of sentient and inanimate motion, the state of becoming, which is central to his nonhumanist metaphysics, as an aesthetic logic of sensation which is to be derived from the essential process of movement itself (2000, 114-120). Surely, for all its disempowerment, the depiction of walking on screen could fall within this broad affective frame of study - a frame which obliges us to re-consider the minor and the indiscernible as possessing new authority. I must turn to one of the parents of the affective field, Brian Massumi, in order to undertake a closer discussion of affect in relation to movement itself. In the introduction to his Parables for the Virtual (2002) he emphasises the combined process of movement/sensation as the sphere of academic investigation. He points out that there is an essential intellectual shift here, to the consideration of process, and to the consideration of change as traceable process; these elements must be tracked over time and space and also in an empirical context. An empirical context that is not however the simple corporeal one, not the simple assumption of (say for example) walking as cognitive/physical process - so no easy direct representation, but instead - an indeterminate relationship that is a 'conversion or unfolding of the body contemporary [his italics] to its every move' (5). We might almost be in the same territory as Gros and Solnit here, except that in Massumi's application, an immediate reservation must be noted. The power and intensity of affect (the attraction for the scholar is this almost operatic intensity) resists any progression which could be described as 'meaningful' or 'definite expectation'. Rather Massumi describes it as a state of 'static' (ie. wireless static) a line of interference that is 'filled with motion' yet with an impractical motion, "a state of suspense, potentially disruption" (23). To take this to an example, one may turn to Massumi's examination of football on television, and of the spectator's responses to the game. Our obsession, our affective engagement with the process, the ball and the moving and halted figures on the screen, is an attention dedicated to the imminence and potential contained behind the multiple and unexpected combinations of bodily and other interactions upon the field. We have no definite expectations to rely upon, but are caught up in a pleasurable cycle of imminence, one which Massumi points out is a derivative, a 'becoming' of all the contributing elements, not merely in themselves, but in their modulations with oneanother (76). In this context, by contrast, the modulations of walking are returned by comparison to a lack of visibility. For walking to be significant within the affective field 
it would need to develop a capacity for imminence and for a potentiality of event, a scoring of possible goals or creation of beautiful moments. Our understanding of walking is of an expertise whose goals are usually hidden from us. Its actions are not only without ethical connotation, but the placing of every foot would now require a circumstance of dangerous ground, or a prior incapacity on our part, in order to develop imminence in relation to its destination. The assurance of the walker's hard won confidence would need to stumble, or develop unexpected flight if this were the rhythm we were looking for. We would become obsessed in the small frame with the placing of each foot, and behind it, with the degree of distance from its stated destination.

\section{ii. Measuring Human Span through Walking}

We have now reached a point of assessing film's capacity to treat walking as an element in the human condition. Where Deleuze treats walking most explicitly is in the films of Herzog, analysing it under the category of a minor or small action $(1986,188$ 190). This is the action image which bears a much larger significance; our perception of the small action feeding into the significance, and then returning to a renewed understanding of the same reiterated small action. It is the walker whose action in walking is continually rendered "defenceless" because "he is who he is beginning to be and never finishes being small" (190). In a literal sense Deleuze points out it is our awareness of other transport, of the motor-car, which renders the action so helpless; only the extremes of poverty etc. Significance or destination in this respect would be for example the understanding which the audience adopts of the pitiful situation and immediate connectivity between the two walking figures at the close of De Sica's Ladri di Biciclette (1948). Such however is not an example of mere social inequality for Deleuze; in his own discussion of Herzog's cinema this literal situation rises to the status of a metaphysical commentary upon the human condition itself - the smallness of their aspirations, deliberately effected through the smallest of actions itself $(1986,189$ 90). Within the action image of classical cinema therefore, paradoxically, the qualities of walking can thus only be brought to the screen through attention to the largest possible complex of themes anterior to the on-screen activity. Massumi's foot-ball game demonstrates the power of a situation where we allow ourselves to be caught up in imminent anticipation within a larger complex that allows and enables our 90 minutes of football affect. For the walker however, this is the action of persistent presence, that undervalued virtue of capacity or health which spans an entire life. The task of the filmmaker is rendered more difficult because the underlying significance that must be referenced is so vast (and vague) by comparison: not merely economic disadvantage, but also, if we are to fulfil our poetic ambitions as film-makers, the tread of human limitation itself.

\section{The Sphere of Chronology.}

\section{i. Walking as Sign}

The Deleuzian framing of later $20^{\text {th }}$ century film turns to time rather than action, as central concept, with a particular attention to the post-war Neo-realist schools. Tait works within this ethos, and may be profitably considered in relation to his time-image. Lucy Reynolds, writing as another artist, makes the point that hers is a cinema preoccupied with film's inherent capacity to address time, either recording or resurrecting its passage $(2004,65)$. Deleuze's second volume, Cinema 2 (1989) is an exploration of the functioning of his Bergsonian longer duration within modern cinema, the temporal changes which are not open to immediate access, but for which a 
perception must be gradually constructed. Construction is inevitably a process of multiplicity; Deleuze tracks the larger representational problem through the assemblage of its component signs - the chronosigns within film. -Between images here there is not the comfortable association that can impose ethical frameworks upon the web of the protagonist's choices, as was available for the action image. Within the chronological framework the protagonist is positioned as a spectator themselves, helplessly following the playing out of the longer situation 'a cinema of the seer and no longer of the agent [de voyant, non plus d'actant].' (2). Deleuze is responding to a later $20^{\text {th }}$ century without central patterns of belief, even with a perceived crisis of belief, and the temporal cinema is determined by a spacing of interstice, 'a spacing which means that each image is plucked from the void and falls back into it.' (173). The repeated choices made within this externally oriented field enable a greater emphasis instead upon the role of individual directors, as ethical protagonists whose cinematography affirms their own belief perspective within the $20^{\text {th }}$ century thought field. Lest this divide be treated as too emphatic, I might also call on Rodwick's suggestion that the shift in belief is less of a direct break between the modern and the classical, so much as a shift, the emphasis on time opening up 'a potentiality always present' $(2010,108)$. Overall however, a Deleuzian consideration of Tait in this context directs us firmly towards both her choices within film, and the underlying priorities, the preoccupying problems and beliefs, by which they are directed. Walking correspondingly appears, no longer as a distinctive action in its own right, achieving significance (ethical, or social or metaphysical), but rather as an image, a sign within the build up of optical (or sound) sequences, that lead in themselves to a fuller temporal conclusion that she is making as a director. The model for this process which Deleuze most fully applies is famously, the crystal-image, a sign within cinema composed of such reflective complexity that the crystal is the concept which best evokes the number of alternative temporal states which are refracted by the virtual image passing before our eyes (1989, 66-76). Such alternative states are the memories, dream-like states or predictions which simultaneously seed and reflect the circuit of past-present-future within the image.

Thus in Tait's work, Portrait of Ga (1952), her short cinematic essay upon her mother, we would be alert to the crystalline form, by perceiving the double dimension of the film. On the one hand there is the immediate and intimate depiction of personal mannerisms; the elderly subject is at times oblivious and at times half-glancing towards the camera, so that a connection is set up across the third frame. On the other hand, there is Tait's voice-over, the seed which establishes the generational relationship at the start and concludes with the oblique comment 'My mother lives in the windy Orkney Islands: it's certainly a wonderful place to be brought up in.' The intimacy, the landscape and the culture we have participated in, are now positioned as the filmmaker's return to the observed habits and tendencies of her mother's relationship with that environment - a style of smoking or of attending to music. As these alternative states are simultaneously assembled, the life-time of the mother is retracted through child's observations and memories. In this context, when Ga treads carefully over rough and wet ground in feminine shoes at the start of the film, that action is not merely an imminent one, but is part of a sequence that conveys both past and present. For a consideration of the choices inherent in this approach of Tait's it is worth recalling that she was also a medical professional, falling within the belief system of a trained scientist. Children are central amongst her subjects, filmed in rural and urban settings, and in this respect her work can be catalogued as part of a broader post-war preoccupation with their play and leisure activities. Working in this context she is pre- 
figured and also informed by clinical practitioners whose work incorporates early application of grounded research in the observational study of marginalized subjects. Even from the 1920s, the texts of psychology, the accessible studies of Jean Piaget (translated:1926) or Susan Isaacs (1930), were emphasising the importance of a comprehensive data-gathering which sought to avoid prior assumptions within both terminology and perspective. From her own culture Tait may thus be suggested as a film-maker who is immediately receptive to the assemblage of multiple components within the crystalline image, in particular its capacities for evidencing a situation through the selection and observation of data. For the depiction of walking however, this is something of a shift. No longer accorded the impact of signifying action, Ga's walking is one instant instead, amongst the many that make up her daughter's memories - plucked so to speak from the void. Tait must also be observed here as a director who does not choose to develop those memories beyond the most immediate observational level. If this cinema is to render walking in itself as banal data, then to demonstrate capacity as an instance, it must be further recovered and discussed in a temporal context (as Deleuze undertakes with his own examples) to apply deeper significance within that dimension, in terms of what the film can cover, either literally, or in recollection or dream.

\section{ii. Exemplar of Walking: Orquil Burn}

Just as much as Gilbertson, Tait can be placed within an understanding of walking that is informed by the Islands and it is here that she provides a particularly strong cinematic exemplar. One poem of hers, Responsiveness (1960) is a treatment of walking as an account of the development of lifetime skills. The explorations made by children are the starting point, but the poem moves forward to consider the fullness of experience in the ground underfoot in later life. Tait is fascinated by the bodily response; that the walker must learn to encounter and have "transmitted knowledge" of a range of surfaces and impacts.

Not only by messages about surface sensations

But also by actual transmission

Of the jarring of hard stone (Neely 2012, 88-89)

Crucially however, within this pedagogy of walking, the poem resists the metaphor which might have been explicitly played out behind multiple experiences, of immediacy as the hidden reduction of a life-span. This is a discussion of experiential knowledge, of observation rather than of speculation, a limitation within the time-image, where Deleuze demonstrates instead the significance of memory and also hallucination in extending the possibilities of the film-maker's individual self-positioning. By contrast, Tait's fullest consideration of walking within this period, Orquil Burn (1955) is limited to a literal and observational journey across landscape, a departure from the Deleuzian consideration of documentary film, one in which belief also is positioned within the falsehoods which directors must of necessity adopt in order to convey their intent. Deleuze is attentive to the possibilities of this observational cinema, suggesting a category of the organic for a setting "presented as independent of the description which the camera gives of it", however he is also at odds with the implicit claim to veracity 'a supposedly pre-existing reality' for which this stands $(1989,122)$. Orquil Burn is notable as the film upon which John Grierson and Tait disagreed over a need for further editing, and in this respect the independent pre-existing dictates not only subject-matter, but also the very structuring and pacing of its montage. Tait is uncompromisingly preoccupied with experience and observation, and this emphasis must be adopted and accepted by the viewer if they are to respond to her film. In this film the land itself is the subject, or 
rather the burn itself, the water, which flows from the moors, through farmland, to the sea. Such is the principle line of narration, it carries the lilting reel of the sound-track and the spoken passage of narrated description, with every element of the film weaving around this central path - at times moving aside to circle parallel features, modern buildings or bridges, but always returning to the incision of the burn as it climbs within the landscape of the Orkney Islands. A literal depiction of walking occurs within the assemblage of briefly chosen images (but the spoken narrative never refers to it experience overtakes commentary); we thus follow an action that is a smallness for which shot and montage are the only guidance for immediate significance. The motion of water itself is constantly reflected in other motions, the old farmer, his dog and the cows, each walk past one another, criss-crossing within the flickering sunlight of the field. The eyelevel of the viewer at this point remains low, also for example with children, engaged in pre-industrial games, making boats out of flag leaves and sailing them on the burn. It is as we follow the film that we start to appreciate the patterns of generational presence on the land, of rural industry, labour and life are combining with environment, vegetation and the dirty froth of water: all undertaken without resource to dramatic emphasis. At its fullest extent this is the chronology of both post-glacial environment and settlement, observed through a mid $20^{\text {th }}$ century modernist lens. However, occurring only through the visible evidence this knowledge is also organic narrative, without the emphatic facets of the crystal image and resisting affective engagement. The task is how to convey a chronology whose presence is vast but indetectible as it lies before us within the present period. As the film progresses the static (but constantly panning) camera starts to be replaced by one creeping handheld, turning to the burn itself, sliding forward into the darkness and the froth of the water or on the bank, observing the flowers that grow there. This is a walking camera, both a hint of the motion and an acknowledgement of the hidden perspective of a walker following the burn. Climbing out of farmland and up to the moors, the camera continues this angle, turning to the ground on different soil and stopping to look backwards at the path taken, again this is the viewpoint of the walker. Walking plays a central role in Orquil Burn not merely through depiction, or enactment, but also through this decision to employ both the smallness and the repetitive pattern of an activity to alert the viewer to a vaster chronological framework that is overlooked within landscape. It also alerts us to how far the affective qualities within the action image are a human engagement; within landscape the human footprint is highlighted as smaller. The preoccupying problem for Tait lies within maintenance of an observational framework of data gathering, and as a film-maker she is precisely attuned to their choices of montage and timing by which this preferred thought field can be engaged through a cinematic span.

\section{The Mental Sphere: Cinema of Mind}

\section{i. Evasive Walking - Absent Landscape}

Overall, within this essay, walking has been distinguished by its evasiveness: even when it is a central occurrence on screen, it elides the attention of the spectator. Tait's Orquil Burn is uniquely successful, in that cinematic walking comes directly into its own. The visual semiotics of the camera work adjusted to voice-over authoritatively convey function, whilst the underlying discourse of time and space within landscape spans the whole film. In this context also, her MacDiarmid passage cited previously, can be recognised as a parallel action appropriate to its city-scape. Gilbertson possesses the same expertise in walking, but the unique Island qualities she is seeking out constitute an ethnographic landscape in which its relevance is obscured. In contrasting 
these two film-makers it cannot suffice that both are preoccupied with the small action or with the metaphysical condition of the human itself which Deleuze perceives in Hertzog. Tait's animals move at one across the field with the flow of walking, Gilbertson's sheep must be static - tied or penned, to convey attention. Environment and the walking figure must be in alignment, or walking is invisible within this visual medium. Even when the two are in alignment however, Tait's successful demonstration of walking is limited. It is the observational data-gathering of a highly observant scientist, conveying time and space to our attention, but never the jolt of the action image, or the static buzz of affect that would accompany immanent anticipation. Cinema seems doomed by these examples, never to encompass the full conjunction of walking and landscape.

\section{ii. Uncanny Landscape}

To address this problem, I must turn to a commentary upon landscape itself, Nancy's essay Uncanny Landscape. In studying film, Deleuze is concerned with the extension of human perception through a technological process, cinema as an evolutionary method of extending our visual range. Nancy's study here is concerned instead with the limitations of human thinking within the confines of the mind and senses. It explores the concept of landscape, first through the interpretations which we make of it, and then through the very intellectual capacities by which we rationalize it as a perception. The naming or occupation or deification of landscape, might suggest it as a stage for presence but Nancy, having considered these positions, makes the point that landscape is not the container for presence, but itself the entire presence. The absence of deity in this respect is of particular significance, Nancy makes the point that landscape's inability to hold such content, not able to present itself "as a presence or as a representation nor as an absence hidden behind or within the depths of nature" results in withdrawal "withdrawal of the divine itself" $(2005,60)$. An unsettling departure would be troubling enough, but Nancy makes the point that we do not perceive it as a whole, but rather through the passage of time, and the instability of the constant change before us within a landscape experience. For conceptualizing walking, this essay takes up Nancy's conclusion here, as to the estrangement and inaccessibility of landscape as a concept. How might such a concept of landscape be perceived or understood? His response is to turn to the action of walking, for an insight into the process. In becoming aware of landscape we must suspend our passage through its process, we must separate ourselves, empty out presence, and undertake "the step [le pas] of the opening itself". This is treated as both action and representative thought process:

'This step is the immobilization in which forward movement is grasped as a basis or a "footing," a span of the hand, the marking out of a measure according to which a world can be laid out. The walker stops, and his step becomes that of a compass, the angle and amplitude of a disposition of space, on whose step - at whose threshold, at whose point of access - a gaze presents itself as gaze.'(62).

My own work cannot address what may be encountered here, but observes rather the method for approaching so difficult a task; in order for the halt to occur, there must first have been the complex but un-regarded action of walking. In Nancy's perception of landscape it is a tool to reach something central, for which there is no other route of access, and this function of measurement and engagement occurs precisely through its own limited scale. No-one has walked - nothing physical, we are in the mind, yet 
walking has-will-have-has-always occurred and the landscape has been encompassed by it.

The extended camera has visualized walking, but with frustrations, yet the internal camera of the mind allows us an instantaneous access to the step as a conceptual vessel for landscape itself. Could this be translated into the cinematic - if I provide an example, will it even be relevant to the reader's own conceptualization? A question is asked of film here, which the medium does not yet need to have answered. If it were translated, the action would be slight, but an occurrence which drew together the entire film. It possesses a screen presence already within our thought, a lack of physicality which flashes across the mind's eye with the speed of a brief take. What must be noted is that the rigour of the Deleuzian chain of action or time-frame is lost here: thoughts are open to distraction and circulate without chronology. When cinema is treated as a tool to convey the awkwardness of walking, we discover the spaces beyond its current behaviours.

\section{Conclusion}

On the Islands the two women film their subjects, perceiving the slightest of adjustments, alert to the visual semiotics of film. They are capable of raising the invisible to the status of observed instance; their subject is the human condition, their framing the landscape. Walking is a favourite activity for both, but lacks the immediate and emphatic rewards of ethical response or affective imminence. When placed within a longer chronological time-frame, it records the banalities of memory, or plays out the human subject against the geological landscape. Cinema is however a mere camera, a technology. The mind also has visual capacity (Nancy reminds us), and the simple function of walking is so central for us that it can also be a tool for mental perception. Gilbertson and Tait each demonstrate the practical and theoretical capacities of cinema when exploring the preoccupations of culture and period, but also sit within its overarching limitations. For walking to emerge as significant element within cinema that medium must break with its own conventions and take up the creative potentiality which underpins our own mental re-imagining in landscape: the ordered visual semiotic of attention does not suffice.

\section{References.}

Alexander, R. McNeill 2005 'Walking Made Simple' Science, New Series 308, (5718): 58-59 doi: 02-11-2016 23:01 UTC

Adolph, Karen E., Beatrix Vereijken and Patrick E. Shrout 2003 'What Changes in Infant Walking and Why' Child Development 74 (2): 475-497 doi: 02-11-2016 22:36 UTC

Bogue, Ronald 2003 Deleuze on Cinema London: Routledge

Deleuze, Gilles 1986 Cinema I The Movement-Image London: Continuum 
Deleuze, Gilles 1989 Cinema 2: The Time-Image London: Continuum

Durgin, Frank H. 2009 'When Walking Makes Perception Better' Current Directions in Psychological Science 18 (1): 43-47 doi: 02-11-2016 22:50 UTC

Kennedy, Barbara M. 2000 Deleuze and Cinema: The Aesthetics of Sensation Edinburgh: Edinburgh University press

Gilbertson, Jenny 1931 Shetland Dairy National Library of Scotland: Written Archives, Papers from Individuals. Unpublished Ms. 4/6/10

Gros, Frédéric 2014 A Philosophy of Walking London: Verso

Isaacs, Susan 1930 Intellectual Growth in Young Children London: Routledge

Massumi, Brian 2002 Parables for the Virtual: Movement, Affect, Sensation Durham:

Duke University Press

McMahon, Melissa 2016 'The Other Industrial Art: Deleuze, Cinema, Affect and Sport' Deleuze Studies 10 (2), 206 -222 doi: 02-11-2016 22:55 UTC

Paiget, Jean 1926 The Language and Thought of the Child (first English ed.) Whitstable, Latimer Trend

Pipes, Rose (Commissioning Editor) Elizabeth Ewan, Sue Innes and Sian Reynolds 2006 The Biographic Dictionary of Scottish Women from earliest times to 2004 Edinburgh: Edinburgh University Press

Nancy, Jean-Luc 2005 The Ground of the Image New York: Fordham University Press

Neely, Sarah and Ali Smith ed. 2012 Margaret Tait: Poems, Stories and Writings Manchester: Carcanet Press

Pfeiffer, Friedrich and Hirochika Inoue 2007 'Walking: Technology and Biology' Philosophical Transactions: Mathematical, Physical and Engineering Sciences 365 (1850): 3-9 doi: 02-11-2016 22:27 UTC

Reynolds, Lucy 2004 'Margaret Tait: Marks of Time' in A Margaret Tait Reader: Subjects and Sequences ed. Todd, Peter and Benjamin Cook 57-76 London: LUX

Rodwick, D. N. 2010 'The World, Time' in Afterimages of Gilles Deleuze's Philosophy ed. D. N. Rodwick 97-114 Minneapolis: University of Minnesota Press

Solnit, Rebecca 2001 Wanderlust: A History of Walking London: Verso, 